COLON CANCER

\title{
Differential gene expression in colon cancer of the caecum versus the sigmoid and rectosigmoid
}

\author{
K Birkenkamp-Demtroder, S H Olesen, F B Sørensen, S Laurberg, P Laiho, L A Aaltonen, T F Ørntoft
}

Gut 2005;54:374-384. doi: 10.1136/gut.2003.036848

See end of article for authors' affiliations

Correspondence to:

Professor T F Ørntoft

Molecular Diagnostic

Laboratory, Department of

Clinical Biochemistry,

Aarhus University

Hospital/Skejby,

Brendstrupgaardsvej 100

DK- 8200 Aarhus N,

Denmark; orntoft@ki.au.dk

Revised version received 8 June 2004

Accepted for publication

23 June 2004
Background and aims: There are epidemiological, morphological, and molecular differences between normal mucosa as well as between adenocarcinomas of the right and left side of the large bowel. The aim of this study was to investigate differences in gene expression.

Methods: Oligonucleotide microarrays (GeneChip) were used to compare gene expression in 45 single samples from normal mucosa and sporadic colorectal carcinomas (Dukes' B and C) of the caecum compared with the sigmoid and rectosigmoid. Findings were validated by real time polymerase chain reaction.

Results: Fifty eight genes were found to be differentially expressed between the normal mucosa of the caecum and the sigmoid and rectosigmoid $(p<0.01)$, including pS2, S100P, and a sialyltransferase, all being expressed at higher levels in the caecum. A total of 118 and 186 genes were differentially expressed between normal and right or left sided tumours of the colon, showing more pronounced differences in Dukes' $C$ than B tumours. Thirty genes differentially expressed in tumour tissue were common to adenocarcinomas of both sides, including known tumour markers such as the matrix metalloproteinases. Keratins 8, 19, and 20 as well as carbonic anhydrases (II, IV, VII) showed side specific expression and were downregulated in left sided tumours whereas teratocarcinoma growth factor and cyclooxygenase 2 (COX-2) were upregulated in left sided adenocarcinomas. Immunohistochemical analysis confirmed differences in side specific expression for cytokeratin 20 and COX-2.

Conclusions: Differences in gene expression between normal mucosa as well as between adenocarcinomas of the caecum and sigmoid or rectosigmoid exist and should be taken into account when examining new targeted therapeutic regimens.
M ultiple differences between right sided (RCC) and left sided (LCC) sporadic colon adenocarcinomas with regard to epidemiological, morphological, and molecular characteristics suggest that the mechanisms of sporadic colorectal carcinogenesis may differ according to tumour location. ${ }^{1}$ Cancers of the right and left colon may form different but related groups of tumours because of their different embryological origin (midgut and hindgut, respectively) and different exposure to bowel content. Colon cancer has a different prevalence at varying ages, in high and low incidence nations, and in men and women. RCCs are more common in females, LCCs in males. ${ }^{2}$ There is also a difference in clinical presentation, in prognosis, and possibly in genetic and environmental epidemiology (see review by Iacopetta ${ }^{3}$ ). Furthermore, it has been suggested that a mechanism exists that promotes the progression of mucosal lesions to invasive cancers in the left colon and rectum whereas a de novo pathway from depressed type lesions may be implicated in cancers of the right colon. ${ }^{4}$ No difference has been found in the distribution of Dukes' stages or in operative mortality between right and left sided sporadic colon cancers. Despite their higher tumour diameter and twofold higher rate of undifferentiated carcinomas, the prognosis of right sided tumours is relatively better than that of left sided tumours, and it has been hypothesised that this could be due to the better blood and lymph supply providing more efficient local tumour defence. ${ }^{5}$ Recurrence and survival are similar between RCC and LCC $^{6}$ whereas response to 5-fluorouracil treatment is significantly better in RCC. ${ }^{7}$

Two studies suggest that molecular differences in gene expression exist between right and left sided colon cancers. Kapiteijn et al showed significantly higher expression of nuclear $\beta$-catenin and p53 in rectal cancers compared with proximal cancers. ${ }^{8}$ Fric et al showed significantly higher expression of cytoplasmic c-erbB2, epidermal growth factor receptor (EGFR), proliferating cell nuclear antigen (PCNA), and dipeptidylpeptidase IV (DPP IV) in right sided sporadic colon cancers compared with left sided cancers. ${ }^{9}$ Distal tumours display a higher frequency of $17 \mathrm{p}$ and $18 \mathrm{q}$ allelic loss, p53 accumulation, c-myc expression, and aneuploidy than proximal tumours. Recently, Glebov et al distinguished proximal from distal normal colon mucosa based on gene expression analysis. ${ }^{10}$

To the best of our knowledge there are no expression data available on differences between adenocarcinomas originating from the proximal or distal part of the colon. As this could have a strong impact on molecularly targeted cancer treatment, we wished to elucidate this aspect and gain insight into differential expression of approximately 7000 human genes of right sided and left sided Dukes' stage B and $\mathrm{C}$ adenocarcinomas as well as normal colon mucosa.

\section{MATERIALS AND METHODS}

Tissue samples, patient information, and RNA isolation

Tissue samples, patient information, and RNA isolation are provided in detail as supplementary data (these data can be viewed on the Gut website at http://www.gut.com/

Abbreviations: LCC, left sided colon cancer; RCC, right sided colon cancer; UG cluster, UniGene cluster (http://www.ncbi.nlm.nih.gov/ UniGene); EGFR, epidermal growth factor receptor; PCNA, proliferating cell nuclear antigen; DPP IV, dipeptidylpeptidase IV; RT-PCR, reverse transcription-polymerase chain reaction; COX-2, cyclooxygenase 2; MSS, microsatellite stable; CA, carbonic anhydrase; MMP, matrix metalloproteinase 


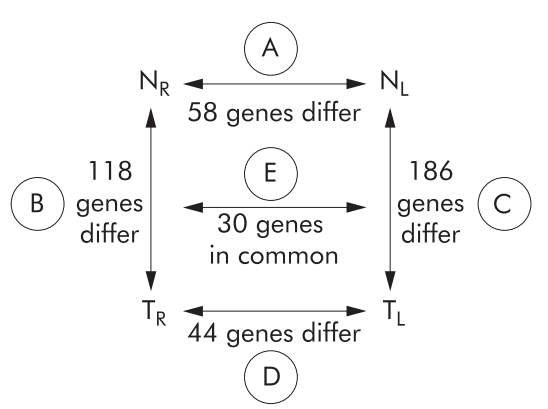

Figure 1 Schematic overview of the five different comparison groups $(A-E)$. Comparison $(A)$ : normal right sided colon mucosa $\left(N_{R}\right)$ from the caecum versus normal left sided $\left(\mathrm{N}_{\mathrm{L}}\right)$ colon mucosa from the sigmoid and rectosigmoid. Comparison (B): normal right sided mucosa from the caecum $\left(N_{R}\right)$ versus matched right sided tumours from the caecum $\left(T_{R}\right)$. Comparison $(C)$ : normal left sided mucosa $\left(N_{L}\right)$ from the sigmoid and rectosigmoid versus left sided tumour $\left(T_{L}\right)$ from the same region of the colon. Comparison (D): right sided tumours $\left(T_{R}\right)$ from the caecum versus left sided tumours $\left(T_{L}\right)$ from the sigmoid and rectosigmoid. Comparison (E): expression differences from normal mucosa to adenocarcinomas that are common between caecum tumours and left sided tumours in the sigmoid and rectosigmoid (comparing (B) versus (C)).

supplemental). Samples from the caecum and rectosigmoid or sigmoid were obtained fresh from surgery and immediately transferred to a solution containing sodium dodecyl sulphate and guanidinium isothiocyanate, snap frozen in liquid nitrogen, and stored at $-80^{\circ} \mathrm{C}$.

Samples consisted of biopsies from the superficial nonnecrotic part of tumours and/or normal mucosa biopsies taken from the oral resection margin. All tumour samples were staged as either Dukes' B (eight from the left colon, five from the caecum) or Dukes' C (seven from the left colon, five from the caecum).

Supplementary table 1 shows detailed clinicopathological information-for example, location of samples in the colon and TNM status (see the Gut website at http://www.gut.com/ supplemental). All 15 left sided and 9/10 right sided tumours $(90 \%)$ were invasive adenocarcinomas; one was an invasive mucinous adenocarcinoma. Six of 10 right sided tumours $(60 \%)$ were moderately differentiated, $3 / 10$ (30\%) were poorly differentiated, and 1/10 (10\%) was well differentiated. Ten of 15 left sided tumours (67\%) were moderately differentiated, $4 / 15(27 \%)$ were poorly differentiated, and $1 / 15(6 \%)$ was well differentiated. The approximate percentages of the volume fractions of tumour cells and stromal cells were semi quantitatively estimated using paraffin embedded diagnostic tissue sections. More than half of the tumour samples showed more than $70 \%$ malignant cells. We hypothesise that the percentage of tumour cells is probably higher in the arrayed samples than in the screened paraffin embedded diagnostic histological tissue sections, as the latter represents the whole invasive tumour in the bowel wall. Informed consent was obtained from all patients. All tumours were sporadic. The local scientific ethics commission approved the project.

Total RNA was isolated from approximately $50 \mathrm{mg}$ of single tissue samples using a Polytron homogeniser followed by treatment with Trizol (Invitrogen, Carlsbad, California, USA) according to the manufacturer's instructions. GeneChip (Affymetrix Inc., Santa Clara, California, USA) analysis of single samples was carried out on 10 samples from the caecum $(65 \mathrm{~B}, 66 \mathrm{~B}, 73 \mathrm{~B}, 120 \mathrm{~B}, 137 \mathrm{~B}, 90 \mathrm{C}, 126 \mathrm{C}, 145 \mathrm{C}, 138 \mathrm{C}$, and 162C), five Dukes' stage B (median age 76 years) and five Dukes' stage C (median age 66 years). Each of the tumours was accompanied by a corresponding matched normal mucosa sample at the same location from the same patient (median age 70 years). Matched samples were given the same sample number, differentiated by " $\mathrm{N}$ " for normal and "B" or "C" for Dukes' B or Dukes' C tumours. Left sided colon samples comprised eight Dukes' stage B (median age 76 years), seven Dukes' stage C (median age 68 years), and 10 "normal mucosa" samples (median age 69 years). Five of these tumours (201C, 202B, 203B, 204C, and 208C) were accompanied by a corresponding matched normal sample at the same location from the same patient. The remaining five normal mucosa samples $(157 \mathrm{~N}, 161 \mathrm{~N}, 179 \mathrm{~N}, 195 \mathrm{~N}$, and $205 \mathrm{~N}$ ) and 10 tumour samples (16B, 237B, 239B, 54B, 127B, 58C, 74C, 85C, 91C, and 96C) were obtained from an independent set of samples of individual patients who underwent resection of the sigmoid or rectosigmoid colon.

\section{cRNA preparation, array hybridisation and scanning, and RT-PCR}

cRNA preparation, array hybridisation, and scanning are provided in detail as supplementary data, including supplementary tables 1-7 (see the Gut website at http://www.gut. com/supplemental).

\section{Data analysis and selection of genes}

Data analysis and selection of genes is provided in detail as supplementary data (see the Gut website at http://www.gut. com/supplemental). Comparison analysis was done using Microarray Suite 5.0 (MAS 5.0), MicroDB 3.0 (MDB 3.0), and Datamining Tool 3.0 (DMT 3.0) (Affymetrix) applying the Affymetrix specific software "Statistical Expression Algorithms". Five different comparison groups (A-E) were established and a schematic overview in given in fig 1 and described in detail in the supplementary data (see the Gut website at http://www.gut.com/supplemental).

For all comparisons, several filterings were made to obtain solid and consistent data. To exclude genes with minor or only individual importance, genes were excluded if more than $80 \%$ (comparison $\mathrm{A}$ ) or $70 \%$ (B and $\mathrm{C}$ ) of all datasets were accompanied by a "detection" call of "absent". Genes were included if more than $80 \%$ (B and C) or $70 \%$ (D) of the comparisons were accompanied by a "change" call of increased or decreased. For statistical analysis, an Affymetrix software integrated Mann-Whitney U test was applied to the signal data of the groups compared with each other. Significance was set at a $\mathrm{p}$ value of $\mathrm{p} \leqslant 0.05$.

\section{Real time PCR, normalisation of RT-PCR data, and microsatellite analysis}

Real time PCR, normalisation of RT-PCR data, and microsatellite analysis are described in detail as supplementary data (see the Gut website at http://www.gut.com/supplemental).

\section{Immunohistochemistry}

Formalin fixed paraffin embedded sections from the normal mucosa and matched tumour tissue were stained with monoclonal mouse antihuman cyclooxygenase 2 (COX-2) (cat No 35-8200; Zymed, AH-diagnostisk, Denmark), diluted 1:300, or monoclonal mouse antihuman cytokeratin 20 (cat. No M7019; Dako Cytomation, Denmark), diluted 1:100, as described in detail in the supplementary data (see the Gut website at http://www.gut.com/supplemental).

\section{RESULTS}

Using Affymetrix GeneChip oligonucleotide microarrays, we analysed gene expression of 45 colonic samples. The expression profile of 10 sporadic adenocarcinomas of

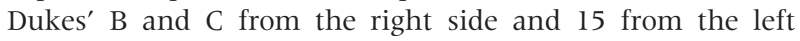
side were compared with 20 normal colon mucosa samples, 10 matched samples from the right and 10 partly matched samples from the left side. Gene expression differences were determined between: (A) normal mucosa of the right and left 
Table 1 Fifty eight genes differentially expressed more than threefold $(p<0.01)$, comparing normal mucosa from the caecum to that of the sigmoid or rectosigmoid

\begin{tabular}{|c|c|c|c|c|c|c|c|c|}
\hline Probe set ID & Gene name & Symbol & $\begin{array}{l}\text { UG } \\
\text { cluster }\end{array}$ & $\begin{array}{l}\text { Cyto } \\
\text { band }\end{array}$ & $\begin{array}{l}\text { Ncae } \\
\text { medt }\end{array}$ & $\begin{array}{l}\text { Nsig } \\
\text { med } \ddagger\end{array}$ & $\mathrm{FC} \S$ & p Valueq \\
\hline D13897_rna2_at & DNA peptide YY & & Hs. 169249 & $17 q 21.1$ & 54 & 103 & 1.9 & 0.002 \\
\hline D14662_at & $\begin{array}{l}\text { Antioxidant protein } 2 \text { (non-selenium glutathione } \\
\text { peroxidase, acidic calcium independent } \\
\text { phospholipase A2) }\end{array}$ & KIAA0106 & Hs. 120 & $1 q 24.1$ & 471 & 918 & 2.0 & 0.005 \\
\hline D37931_at & Ribonuclease, RNase A family, 4 & RNASE4 & Hs. 283749 & 14 & 214 & 337 & 1.6 & 0.001 \\
\hline D42043_at & KIAA0084 protein & KIAA0084 & Hs.79123 & $3 \mathrm{p} 24.3$ & 220 & 142 & -1.5 & 0.003 \\
\hline D84454_at & $\begin{array}{l}\text { Solute carrier family } 35 \text { (UDP-galactose } \\
\text { transporter), member } 2\end{array}$ & SLC35A2 & Hs. 21899 & Xp11.23 & 152 & 247 & 1.6 & 0.001 \\
\hline HG1067-HT1067_r_at & Mucin (Gb:M22406) & & & & 196 & 479 & 2.4 & 0.001 \\
\hline HG2348-HT2444_s_at & Peptide Yy & & Hs. 169249 & & 284 & 575 & 2.0 & 0.007 \\
\hline HG273-HT273_s_at & Fibrinogen $A$ alpha polypeptide alt. splice $3 \mathrm{E}^{*}$ & & Hs.351593 & $4 q 28$ & 37 & 136 & 3.7 & 0.007 \\
\hline J03600_at & Arachidonate 5 -lipoxygenase & ALOX5 & Hs. 89499 & $10 \mathrm{q} 11.2$ & 92 & 51 & -1.8 & 0.006 \\
\hline J04164 at & Interferon induced transmembrane protein 1 (9-27) & IFITMI & Hs. 146360 & 11 & 1494 & 963 & -1.6 & 0.007 \\
\hline J04809_rnal_at & Cytosolic adenylate kinase (AKI) gene. & & Hs.76240 & $9 q 34.1$ & 75 & 116 & 1.5 & 0.003 \\
\hline J05036_s_at & Cathepsin $E^{*}$ & CTSE & Hs. 1355 & 1931 & 39 & 138 & 3.5 & 0.002 \\
\hline J05582_s_at & Mucin 1, transmembrane & $\mathrm{MUCl}$ & Hs.89603 & $\operatorname{lq} 21$ & 586 & 899 & 1.5 & 0.005 \\
\hline K02765_at & Complement component 3 & C3 & Hs. 284394 & $19 p 13.3$ & 472 & 216 & -2.2 & 0.007 \\
\hline L42379_at & Quiescin Q6 & QSCN6 & Hs.77266 & $\operatorname{lq} 24$ & 529 & 1150 & 2.2 & 0.000 \\
\hline L77701_at & $\begin{array}{l}\text { COX17 (yeast) homologue, cytochrome } \\
\text { c oxidase assembly protein }\end{array}$ & $\operatorname{cox} 17$ & Hs. 16297 & $3 q 13.32$ & 270 & 429 & 1.6 & 0.003 \\
\hline M11433_at & Retinol binding protein 1, cellular & RBPl & Hs. 101850 & $3 q 23$ & 54 & 25 & -2.1 & 0.008 \\
\hline M12529_at & Apolipoprotein E & APOE & Hs. 169401 & $19 q 13.2$ & 922 & 489 & -1.9 & 0.007 \\
\hline M16364_s_at & Creatine kinase, brain* & CKB & Hs. 173724 & $14 \mathrm{q} 32$ & 614 & 2300 & 3.7 & 0.008 \\
\hline M16938_s_at & Homeo box $\mathrm{C} 6$ & HOXC6 & $\mathrm{Hs} .820$ & $12 q 12$ & 55 & 27 & -2.0 & 0.002 \\
\hline M27281_at & Vascular endothelial growth factor & VEGF & Hs.73793 & $6 p 12$ & 42 & 14 & -2.1 & 0.002 \\
\hline M36341_at & ADP-ribosylation factor 4 & ARF4 & Hs.75290 & $3 \mathrm{p} 21.2$ & 693 & 1086 & 1.6 & 0.005 \\
\hline M77144_rnal at & 3-Beta-hydroxysteroid dehydrogenase* & & $\mathrm{Hs} .825$ & 1 lpl3.1 & 109 & 18 & -5.4 & 0.005 \\
\hline M80244 at & Solute carrier family 7 , member 5 & SLC7A5 & Hs. 184601 & $16 q 24.3$ & 129 & 63 & -2.0 & 0.002 \\
\hline M84424_at & Cathepsin E (CTSE) gene & & & & 17 & 53 & 2.7 & 0.005 \\
\hline M86849_at & Gap junction protein, beta 2, 26kD (connexin 26) & GJB2 & Hs.5566 & $13 q 11$ & 89 & 56 & -1.6 & 0.007 \\
\hline M97925_rnal_at & Defensin $5^{\star}$ & & Hs.72887 & 8pter-p21 & 215 & 35 & -6.1 & 0.002 \\
\hline M98539_at & Prostaglandin D2 synthase gene & & & & 569 & 221 & -2.6 & 0.001 \\
\hline S80562_at & Calponin 3, acidic & CNN3 & Hs. 194662 & $1 \mathrm{p} 22$ & 127 & 79 & -1.6 & 0.001 \\
\hline U03057_at & Actin bundling protein (HSN) & SNL & Hs. 118400 & $7 \mathrm{p} 22$ & 312 & 200 & -1.6 & 0.002 \\
\hline U24576_at & $\begin{array}{l}\text { LIM domain only } 4 \text {; breast tumour } \\
\text { autoantigen complete sequence }\end{array}$ & LMO4 & Hs.3844 & $1 \mathrm{p} 22.3$ & 97 & 52 & -1.9 & 0.007 \\
\hline U33632_at & $\begin{array}{l}\text { Potassium channel, subfamily } \mathrm{K} \text {, } \\
\text { member } 1 \text { (TWIK-1) }\end{array}$ & KCNK1 & Hs.79351 & $1 q 42$ & 52 & 87 & 1.7 & 0.002 \\
\hline U50553_at & $\begin{array}{l}\text { DEAD/H (Asp-Glu-Ala-Asp/His) box } \\
\text { polypeptide } 3\end{array}$ & DDX3 & Hs. 147916 & Xp11.3 & 63 & 42 & -1.5 & 0.008 \\
\hline U61262_at & Neogenin (chicken) homolog 1 & NEO1 & Hs.90408 & $15 q 22.3$ & 139 & 210 & 1.5 & 0.003 \\
\hline U66661_at & $\begin{array}{l}\text { Gamma-aminobutyric acid (GABA) } \\
\text { A receptor, epsilon }\end{array}$ & GABRE & Hs. 22785 & $\mathrm{Xq} 28$ & 60 & 32 & -1.9 & 0.007 \\
\hline U73514_at & Hydroxyacyl-coenzyme A dehydrogenase, type II & $\mathrm{HADH} 2$ & Hs. 171280 & Xpl 1.2 & 298 & 462 & 1.6 & 0.009 \\
\hline U75679_at & Stem-loop (histone) binding protein & SLBP & Hs.75257 & $4 \mathrm{pl} 6.3$ & 65 & 43 & -1.5 & 0.007 \\
\hline U81599_at & Homeo box B13* & HOXB13 & Hs.66731 & $17 q 21.2$ & 33 & 240 & 7.2 & 0.001 \\
\hline U90065_s_at & $\begin{array}{l}\text { Potassium channel, subfamily K, } \\
\text { member } 1 \text { (TWIK-1) }\end{array}$ & KCNKI & Hs.79351 & $1 \mathrm{q} 42$ & 160 & 293 & 1.8 & 0.002 \\
\hline U90911_at & Clone 23652 sequence & & Hs. 171807 & - & 463 & 304 & -1.5 & 0.000 \\
\hline X00371_rnal_at & Myoglobin gene (exon 1) & & Hs.118836 & $22 q 13.1$ & 213 & 108 & -2.0 & 0.004 \\
\hline X52003_at & pS2 protein; trefoil factor 1* $^{*}$ & TFF1 & Hs. 1406 & $21 \mathrm{q} 22.3$ & 313 & 2413 & 7.7 & 0.000 \\
\hline X59770_at & Interleukin 1 receptor, type II & IL1R2 & Hs. 25333 & $2 q 12$ & 160 & 427 & 2.7 & 0.001 \\
\hline X61118 rnal at & LIM domain only 2 (rhombotin-like 1) TTG-2 & $\mathrm{LMO} 2$ & Hs. 184585 & $11 \mathrm{pl3}$ & 63 & 38 & -1.7 & 0.005 \\
\hline X63187_at & WAP four-disulfide core domain $2^{*}$ & WFDC2 & Hs. 2719 & $20 q 12$ & 134 & 714 & 5.3 & 0.002 \\
\hline X64072_s_at & Integrin, beta 2 (antigen CD18), (mac-1) & ITGB2 & Hs.83968 & $21 \mathrm{q} 22.3$ & 123 & 64 & -1.9 & 0.005 \\
\hline X65614_at & ${ }^{*} \mathrm{~S} 100$ calcium-binding protein $\mathrm{P}^{*}$ & S100P & Hs. 2962 & 4 pl6 & 170 & 1293 & 7.6 & 0.001 \\
\hline X74570_at & $\begin{array}{l}\text { Sialyltransferase } 4 C \text { (beta-galactosidase } \\
\text { alpha-2,3-sialytransferase)* }\end{array}$ & SIAT4C & Hs.75268 & $11 q 23$ & 87 & 486 & 5.6 & 0.001 \\
\hline X75042_at & $\begin{array}{l}\text { v-rel avian reticuloendotheliosis viral } \\
\text { oncogene homolog }\end{array}$ & REL & Hs. 44313 & $2 p 13-p 12$ & 64 & 33 & -2.0 & 0.005 \\
\hline X78924_at & Zinc finger protein 266 & ZNF266 & Hs.118281 & 19 & 43 & 24 & -1.9 & 0.002 \\
\hline X85545_at & Protein kinase, $X$-linked & PRKX & Hs. 147996 & Xp22.3 & 39 & 24 & -1.6 & 0.007 \\
\hline X87159_at & $\begin{array}{l}\text { Sodium channel, non-voltage-gated } 1 \text {, } \\
\text { beta (Liddle syndrome)* }\end{array}$ & SCNNIB & Hs.37129 & $16 p 12.2$ & 79 & 393 & 5.0 & 0.008 \\
\hline X97324_at & Adipose differentiation-related protein & ADFP & Hs.3416 & $9 p 21.3$ & 194 & 112 & -1.7 & 0.001 \\
\hline Y00503_at & Keratin 19 & KRT19 & Hs. 182265 & $17 q 21$ & 1422 & 2968 & 2.1 & 0.001 \\
\hline Y11251_at & $\begin{array}{l}\text { Splicing factor, arginine/serine-rich } 2, \\
\text { interacting protein }\end{array}$ & SFRS2IP & Hs. 51957 & $12 q 12$ & 69 & 41 & -1.7 & 0.004 \\
\hline Z29090_at & $\begin{array}{l}\text { Phosphoinositide-3-kinase, catalytic, } \\
\text { alpha polypeptide }\end{array}$ & PIKЗСA & Hs. 85701 & $3 q 26.3$ & 33 & 18 & -1.7 & 0.004 \\
\hline Z35278_at & $\begin{array}{l}\text { Runt-related transcription factor } 3 \\
\text { PEBP } 2 \mathrm{aCl} \text { acute myeloid leukaemia }\end{array}$ & RUNX3 & Hs. 170019 & $1 p 36$ & 47 & 30 & -1.6 & 0.008 \\
\hline Z48541_at & Protein tyrosine phosphatase, receptor type, $\mathrm{O}^{*}$ & PTPRO & Hs.258609 & $12 \mathrm{p} 13.3$ & 19 & 61 & 3.0 & 0.008 \\
\hline
\end{tabular}

*Twelve of the 58 genes showed fold changes more than threefold.

†Ncae med, median derived from "signal" of 10 normal mucosae of the caecum.

\#Nsig med, median derived from "signal" of 10 normal mucosae of the sigmoid or rectosigmoid.

SFC, fold change, corresponding to the "signal ratio" of Nsig med/Ncae med, was calculated from the "signal log ratio".

Ip value, probability that a variant would assume a value greater than or equal to the observed value strictly by chance.

UG cluster, UniGene cluster (http://www.ncbi.nlm.nih.gov/UniGene). 
Table 2 Twenty two genes differentially expressed more than fourfold $(p<0.01)$, comparing normal mucosa to matched Dukes' $B$ or $C$ adenocarcinomas of the caecum

\begin{tabular}{|c|c|c|c|c|c|c|c|c|c|c|c|c|c|}
\hline Probe set ID & Gene name & Symbol & $\begin{array}{l}\text { UG } \\
\text { cluster }\end{array}$ & $\begin{array}{l}\text { Cyto } \\
\text { band }\end{array}$ & $\begin{array}{l}\text { Ncae } \\
\text { med }^{*}\end{array}$ & IQ N† & $\begin{array}{l}\text { Bcae } \\
\text { medf }\end{array}$ & IQ B & $\begin{array}{l}\text { Ccae } \\
\text { med } \S\end{array}$ & IQC & $\begin{array}{l}\text { Avg } \\
\text { FCब } \\
\text { NvB }\end{array}$ & $\begin{array}{l}\text { Avg FC } \\
\text { NvC }\end{array}$ & p Value \\
\hline AF001548_rnal_at & Chromosome 16 BAC clone & & Hs.78344 & $16 p 13.13$ & 1165 & 1437 & 99 & 125 & 261 & 118 & -8.0 & -5.8 & 0.000 \\
\hline D10667_s_at & $\begin{array}{l}\text { Smooth muscle myosin } \\
\text { heavy chain }\end{array}$ & & & & 77 & 153 & 18 & 3 & 18 & 18 & -10.2 & -11.2 & 0.000 \\
\hline J03507_at & $\begin{array}{l}\text { Complement protein } \\
\text { component C7 }\end{array}$ & C7 & Hs.78065 & $5 p 13$ & 88 & 16 & 10 & 10 & 11 & 8 & -6.4 & -4.6 & 0.000 \\
\hline J05096_rnal_at & $\begin{array}{l}\text { NaK-ATPase alpha } 2 \\
\text { (ATP1A2) }\end{array}$ & & Hs.34114 & $1 q 21-q 23$ & 15 & 7 & 4 & 3 & 9 & 5 & -5.5 & -1.2 & 0.002 \\
\hline M14539_at & $\begin{array}{l}\text { Coagulation factor XIII, } \\
\text { Al polypeptide }\end{array}$ & $\mathrm{F} 13 \mathrm{~A} 1$ & Hs. 80424 & $6 p 25.3$ & 159 & 60 & 42 & 59 & 52 & 11 & -4.6 & -3.1 & 0.000 \\
\hline M63379_at & TRPM-2 protein gene & & & & 918 & 1022 & 285 & 328 & 255 & 144 & -5.1 & -4.0 & 0.000 \\
\hline M63603_at & Phospholamban & PLN & Hs. 85050 & $6 q 22.1$ & 29 & 19 & 7 & 6 & 20 & 12 & -7.1 & -1.4 & 0.003 \\
\hline M77349_at & Transforming growth factor & TGFBI & Hs. 118787 & $5 q 31$ & 253 & 118 & 582 & 654 & 1933 & 199 & 2.1 & 5.9 & 0.003 \\
\hline S67156_at & $\begin{array}{l}\text { Aspartoacylase } \\
\text { (aminoacylase 2) }\end{array}$ & ASPA & Hs.32042 & 17 pter & 25 & 10 & 7 & 6 & 2 & 7 & -5.0 & -4.4 & 0.000 \\
\hline U18018_at & Ets variant gene 4 & ETV4 & Hs.77711 & $17 q 21$ & 67 & 33 & 340 & 92 & 261 & 79 & 3.3 & 4.4 & 0.000 \\
\hline U20758_rnal_at & Osteopontin & & Hs.313 & $4 q 21-q 25$ & 15 & 2 & 80 & 128 & 120 & 298 & 4.6 & 12.8 & 0.000 \\
\hline U37283_at & $\begin{array}{l}\text { Microfibril associated } \\
\text { glycoprotein-2 }\end{array}$ & MAGP2 & Hs.58882 & $12 p 13.1$ & 53 & 28 & 17 & 10 & 7 & 9 & -6.2 & -2.5 & 0.008 \\
\hline U70663_at & Kruppel-like factor 4 ; hEZF & KLF4 & Hs.7934 & $9 q 31$ & 587 & 395 & 124 & 127 & 71 & 34 & -3.0 & -10.3 & 0.001 \\
\hline U71207_at & $\begin{array}{l}\text { Eyes absent (Drosophila) } \\
\text { homologue } 2\end{array}$ & EYA2 & Hs.29279 & $20 \mathrm{q} 13.1$ & 44 & 36 & 20 & 4 & 6 & 4 & 1.1 & -6.4 & 0.016 \\
\hline U77180_at & $\begin{array}{l}\text { Small inducible cytokine } \\
\text { subfamily A }\end{array}$ & SCYA19 & Hs.50002 & $9 p 13$ & 104 & 50 & 3 & 7 & 3 & 7 & -10.4 & -13.6 & 0.002 \\
\hline X00371_rnal_at & Myoglobin gene (exon 1) & & Hs.118836 & $22 q 13.1$ & 213 & 120 & 44 & 32 & 65 & 48 & -7.1 & -3.4 & 0.000 \\
\hline X03350_at & $\begin{array}{l}\text { Alcohol dehydrogenase 1B } \\
\text { (class I) }\end{array}$ & $\mathrm{ADHIB}$ & Hs.4 & $4 q 21-q 23$ & 85 & 43 & 12 & 5 & 5 & 3 & -9.0 & -17.2 & 0.000 \\
\hline X05232_at & MMP3/stromelysin 1 & MMP3 & Hs. 83326 & $11 \mathrm{q} 22.3$ & 12 & 10 & 165 & 96 & 243 & 544 & 15.5 & 33.6 & 0.000 \\
\hline X07820_at & MMP10/stromelysin 2 & MMP10 & Hs. 2258 & $11 \mathrm{q} 22.3$ & 4 & 4 & 28 & 42 & 20 & 10 & 10.1 & 7.1 & 0.001 \\
\hline X54162_at & Leiomodin 1 (smooth muscle) & LMODI & Hs.79386 & 1 & 126 & 84 & 21 & 11 & 36 & 9 & -5.3 & -4.5 & 0.000 \\
\hline X54925_at & Matrix metalloproteinase 1 & MMP1 & Hs.83169 & $11 q 22.3$ & 10 & 5 & 248 & 120 & 244 & 1929 & 16.9 & 36.7 & 0.000 \\
\hline X65614_at & $\begin{array}{l}\text { S100 calcium binding } \\
\text { protein P }\end{array}$ & S100P & Hs.2962 & $4 p 16$ & 170 & 304 & 1392 & 1336 & 2087 & 371 & 7.4 & 6.1 & 0.000 \\
\hline $\begin{array}{l}\text { *Ncae med, median } \\
\text { † } \\
\text { †B interquartile, dif } \\
\text { \$Bcae med, median } \\
\text { SCcae med, median } \\
\text { FFC, fold change, cc } \\
\text { UG cluster, UniGene }\end{array}$ & $\begin{array}{l}\text { terence between the } / \text { th and } \\
\text { derived from "signal" of five } \\
\text { derived from "signal" of five } \\
\text { orresponding to the "signal rat } \\
\text { cluster (http://www.ncbi.nlm. }\end{array}$ & Dukes' Co & $\begin{array}{l}\text { denocarcinom } \\
\text { ne med/Bcae r } \\
\text { niGene). }\end{array}$ & $\begin{array}{l}\text { mas of the ca } \\
\text { med or Nca }\end{array}$ & rect & Conot & 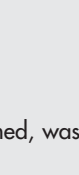 & ater & te & & & ratio". & \\
\hline
\end{tabular}

side; (B) normal mucosa and Dukes' B or C adenocarcinomas of the right side; (C) normal mucosa and Dukes' B or C adenocarcinomas of the left side; (D) Dukes' $\mathrm{B}$ or $\mathrm{C}$ adenocarcinomas of the right and left side; and finally (E), differentially expressed genes in the right sided colon from comparison $\mathrm{B}$ with those in the left sided colon from comparison C (fig 1).

\section{Comparison A: normal caecum versus sigmoid/ rectosigmoid}

By comparing normal mucosa samples from 20 different patients-namely, 10 right sided from the caecum to 10 left sided from the sigmoid or rectosigmoid-we identified 160 genes showing site specific differential gene expression, being increased or decreased more than 1.5 fold $(\mathrm{p}<0.05$, MannWhitney $U$ test). Fifty eight genes with a $p$ value of $<0.01$ are shown in table $1 ; 12$ of these genes with fold changes more than threefold the median signal are labelled with an asterisk.

The gene encoding the pS2 protein, maintaining the mucosal surface barrier and stimulating repair processes, showed 7.7-fold higher expression in the left than in the right colon. Other differentially expressed genes with a consistent difference were calcium binding protein S100P (7.6-fold), homeodomain protein HOXB13 (7.2-fold), defensin 5 (6.1fold), Gal-beta (1-3/1-4) GlcNAc alpha-2.3-sialyltransferase (5.6-fold), 3-beta-hydroxysteroid dehydrogenase gene (5.4fold), and HE4 extracellular proteinase inhibitor homologue (5.3-fold). Also, the beta subunit of creatine kinase-B, fibrinogen A alpha polypeptide alt. splice 3 E (3.7-fold), cathepsin E, and protein tyrosine phosphatase were among the genes showing more than threefold significantly different expression between the two groups.

\section{Comparison B: normal versus tumour caecum}

By comparing normal mucosa of the caecum to matching caecum adenocarcinomas staged as Dukes' B or C and derived from the same patient, we identified 118 genes significantly up or downregulated more than 2.8-fold $(\mathrm{p}<0.05$, Mann-Whitney $U$ test $)$ in adenocarcinomas compared with normal mucosa (see supplementary table on the Gut website at http://www.gut.com/supplemental). Seventy three showed fold changes of more than fourfold, and of these, 22 genes with a p value of $<0.01$ are shown in table 2 .

A characteristic finding was that most genes $(n=15)$ were downregulated in carcinomas compared with normal mucosa, and only a few were upregulated $(n=7)$. Several matrix metalloproteinases, such as MMP1, MMP3, and MMP10, located in the extracellular space and involved in proteolysis and peptidolysis were highly upregulated in carcinomas, as well as ElA enhancer binding protein (ElAF) (fourfold) and calcium binding protein S100P. TRPM-2 protein (fivefold), complement protein component C7 (fivefold), and NAD+ dependent 15 hydroxyprostaglandin dehydrogenase (PGDH; 16-fold) showed decreased expression.

\section{Comparison C: normal versus tumour sigmoid/ rectosigmoid}

We compared normal mucosa from the left side of the colon to matching adenocarcinomas of Dukes' $\mathrm{B}$ and $\mathrm{C}$ from the 
Table 3 Forty two genes differentially expressed more than fourfold ( $p<0.01$ ), comparing normal mucosa to Dukes' $B$ or $C$ tumours from the sigmoid or rectosigmoid

\begin{tabular}{|c|c|c|c|c|c|c|c|c|c|c|c|c|}
\hline Probe set ID & Gene name & Symbol & $\begin{array}{l}\text { UG } \\
\text { cluster }\end{array}$ & $\begin{array}{l}\text { Cyto } \\
\text { band }\end{array}$ & $\begin{array}{l}\text { Nsig } \\
\text { med }^{*}\end{array}$ & $\begin{array}{l}\mathrm{IQ} \\
\mathrm{N} \dagger\end{array}$ & $\begin{array}{l}\text { Bsig } \\
\text { med } \ddagger\end{array}$ & IQ B & $\begin{array}{l}\text { Csig } \\
\text { med§ }\end{array}$ & IQ C & $\begin{array}{l}\text { Avg } \\
\text { FCף } \\
\text { NvB }\end{array}$ & $\begin{array}{l}\text { Avg FC } \\
\text { NvC }\end{array}$ \\
\hline D84239_at & $\begin{array}{l}\text { Fc fragment of lgG } \\
\text { binding protein }\end{array}$ & FCGBP & Hs. 111732 & $19 q 13.1$ & 2819 & 726 & 233 & 525 & 171 & 408 & -21.0 & -23.4 \\
\hline HG2981-HT3125 & Epican Alt. Splice 1 & & & & 13 & 7 & 58 & 53 & 75 & 43 & 4.3 & 5.6 \\
\hline J03910_rnal_at & Metallothionein-IG gene & MTIG & Hs. 173451 & $16 q 13$ & 2252 & 1934 & 409 & 581 & 148 & 105 & -6.9 & -12.3 \\
\hline J03915_s_at & Chromogranin A & CHGA & Hs. 172216 & $14 q 32$ & 448 & 153 & 62 & 62 & 41 & 20 & -5.0 & -6.1 \\
\hline J04040_at & Glucagon & GCG & Hs. 1460 & $2 q 36$ & 314 & 514 & 27 & 35 & 11 & 6 & -8.7 & -15.5 \\
\hline J04093_s_at & UDP glycosyltransferase 1 family & UGTIA6 & Hs. 284239 & $2 q 37$ & 204 & 78 & 41 & 34 & 35 & 18 & -4.0 & -5.2 \\
\hline J04152_rnal & MISI gene & & Hs.23582 & $1 p 32-p 31$ & 6 & 11 & 66 & 30 & 144 & 509 & 6.9 & 19.0 \\
\hline J05257_at & $\begin{array}{l}\text { MDP4 MDP7 microsomal } \\
\text { dipeptidase }\end{array}$ & DPEP1 & Hs. 109 & $16 q 24.3$ & 26 & 10 & 847 & 790 & 388 & 366 & 20.1 & 7.9 \\
\hline L10373_at & (Clone CCG-B7) sequence & & Hs. 82749 & $\mathrm{Xq11}$ & 310 & 91 & 74 & 77 & 61 & 27 & -4.6 & -5.6 \\
\hline L10955_cds1 & Carbonic anhydrase IV gene & CAIV & & & 1186 & 365 & 194 & 195 & 30 & 19 & -7.2 & -32.7 \\
\hline L1 1708_at & $\begin{array}{l}\text { Hydroxysteroid (17-beta) } \\
\text { dehydrogenase } 2\end{array}$ & HSD17B2 & Hs. 155109 & $16 q 24.1$ & 414 & 71 & 41 & 65 & 22 & 10 & -5.9 & -6.4 \\
\hline L12760_s_at & $\begin{array}{l}\text { Phosphoenolpyruvate } \\
\text { carboxykinase } 1\end{array}$ & PCK1 & Hs. 1872 & $20 q 13.31$ & 755 & 566 & 106 & 145 & 40 & 31 & -4.2 & -11.0 \\
\hline L21998_at & Mucin 2, intestinal/tracheal & MUC2 & Hs.315 & $11 \mathrm{p} 15.5$ & 4189 & 1013 & 1175 & 2355 & 243 & 206 & -4.1 & -14.8 \\
\hline L22524_s_at & Matrilysin gene & & & & 5 & 5 & 37 & 17 & 570 & 683 & 6.1 & 83.2 \\
\hline L76465_at & $\begin{array}{l}\text { Hydroxyprostaglandin } \\
\text { dehydrogenase } 15\end{array}$ & HPGD & Hs.77348 & $4 q 34-q 35$ & 213 & 48 & 61 & 45 & 21 & 22 & -4.5 & -7.7 \\
\hline M12963_s_at & $\begin{array}{l}\text { Alcohol dehydrogenase 1A } \\
\text { (class I), alpha }\end{array}$ & ADHIA & Hs.73843 & $4 q 21-q 23$ & 1724 & 645 & 260 & 649 & 59 & 69 & -7.1 & -38.8 \\
\hline M14758_at & ATP binding cassette, sub-family B & $\mathrm{ABCB} 1$ & Hs.21330 & $7 q 21.1$ & 162 & 66 & 37 & 60 & 33 & 28 & -4.1 & -6.1 \\
\hline M16364_s_at & Creatine kinase- $B$ & CKB & Hs. 173724 & $14 q 32$ & 2300 & 720 & 501 & 693 & 314 & 275 & -4.8 & -13.2 \\
\hline M16801_at & $\begin{array}{l}\text { Nuclear receptor subfamily } 3 \text {, } \\
\text { group C }\end{array}$ & NR3C2 & Hs. 1790 & $4 q 31.1$ & 161 & 34 & 32 & 26 & 13 & 2 & -4.0 & -10.3 \\
\hline M18079_at & $\begin{array}{l}\text { Fatty acid binding protein 2, } \\
\text { intestinal }\end{array}$ & FABP2 & Hs. 282265 & $4 q 28-q 31$ & 184 & 126 & 31 & 23 & 20 & 18 & -4.9 & -10.2 \\
\hline M60047_at & $\begin{array}{l}\text { Heparin binding growth factor } \\
\text { binding protein }\end{array}$ & HBP17 & Hs. 1690 & 4p16-p15 & 143 & 99 & 33 & 32 & 28 & 12 & -4.4 & -4.8 \\
\hline M77349_at & $\begin{array}{l}\text { Transforming growth factor, beta } \\
\text { induced }\end{array}$ & TGFBI & Hs. 118787 & $5 q 31$ & 307 & 145 & 1735 & 787 & 2618 & 1643 & 5.3 & 8.0 \\
\hline M87860_at & S-lac lectin L-14-II (LGALS2) gene & & & & 232 & 129 & 40 & 39 & 12 & 18 & -5.3 & -7.4 \\
\hline M97496_at & $\begin{array}{l}\text { Guanylate cyclase activator 2A } \\
\text { (guanylin) }\end{array}$ & GUCA2A & Hs.778 & $1 p 35-p 34$ & 1931 & 279 & 147 & 150 & 62 & 47 & -15.8 & -44.5 \\
\hline U14528_at & DTD sulfate transporter & SLC26A2 & Hs.29981 & $5 q 31-q 34$ & 620 & 410 & 137 & 182 & 23 & 12 & -4.3 & -20.1 \\
\hline U17077_at & BENE protein & BENE & Hs. 185055 & $2 q 13$ & 1499 & 544 & 214 & 108 & 207 & 212 & -4.3 & -6.2 \\
\hline U70663_at & Kruppel-like factor 4, hEZF & KLF4 & Hs.7934 & $9 q 31$ & 605 & 362 & 76 & 98 & 44 & 56 & -6.2 & -8.8 \\
\hline X52001_at & Endothelin 3 & EDN3 & Hs. 1408 & $20 q 13.2$ & 100 & 44 & 34 & 32 & 6 & 7 & -4.6 & -16.1 \\
\hline X53800_s_at & GRO3 oncogene & GRO3 & Hs.89690 & $4 q 21$ & 21 & 13 & 73 & 49 & 75 & 95 & 5.3 & 5.0 \\
\hline X54489_rnal_at & (MGSA) & MGSA & Hs.789 & $4 q 21$ & 56 & 19 & 262 & 235 & 484 & 601 & 7.8 & 8.4 \\
\hline X54925_at & (Interstitial collagenase) & MMP1 & Hs.83169 & $11 \mathrm{q} 22.3$ & 12 & 7 & 129 & 73 & 945 & 1041 & 7.3 & 31.8 \\
\hline X57579_s_at & Inhibin, beta A (activin A) & INHBA & $\mathrm{Hs} .727$ & $7 p 15-p 13$ & 7 & 9 & 60 & 68 & 433 & 332 & 5.1 & 26.7 \\
\hline X59766_at & Alpha-2-glycoprotein 1, zinc & AZGP1 & Hs.71 & $7 q 22.1$ & 15 & 19 & 333 & 125 & 114 & 83 & 18.8 & 4.4 \\
\hline X59770_at & Interleukin 1 receptor, type II & ILIR2 & Hs. 25333 & $2 q 12-q 22$ & 427 & 185 & 48 & 25 & 65 & 42 & -6.4 & -4.5 \\
\hline X63597_at & Sucrase-isomaltase & $\mathrm{SI}$ & Hs.2996 & $3 q 25.2$ & 37 & 36 & 12 & 13 & 3 & 4 & -8.0 & -14.1 \\
\hline X63629_at & $\begin{array}{l}\text { Cadherin 3, type 1, P-cadherin } \\
\text { (placental) }\end{array}$ & $\mathrm{CDH} 3$ & Hs. 2877 & $16 q 22$ & 14 & 8 & 214 & 76 & 134 & 146 & 11.2 & 6.6 \\
\hline X73501_at & Cytokeratin 20 & KRT20 & Hs.84905 & $17 q 21.1$ & 1553 & 635 & 185 & 130 & 107 & 110 & -5.5 & -12.0 \\
\hline X87159_at & $\begin{array}{l}\text { Sodium channel, } \\
\text { nonvoltage-gated } 1\end{array}$ & SCNNIB & Hs.37129 & $16 p 12.2$ & 393 & 180 & 29 & 51 & 10 & 5 & -8.3 & -22.1 \\
\hline X98311_at & Carcinoembryonic antigen-related & CEACAM7 & Hs.74466 & $19 q 13.2$ & 3817 & 1389 & 462 & 475 & 145 & 114 & -4.1 & -16.3 \\
\hline Y00339_s_at & Carbonic anhydrase II (EC 4.2.1.1) & CA2 & Hs. 155097 & $8 q 22$ & 1096 & 465 & 58 & 112 & 28 & 12 & -20.8 & -27.4 \\
\hline Y00787_s_at & Interleukin 8/MDNCF & IL8 & Hs.624 & $4 q 13-q 21$ & 53 & 260 & 614 & 326 & 1794 & 2320 & 5.4 & 15.5 \\
\hline Z70295_at & GCAP-II (uroguanylin) & GUCA2B & Hs.32966 & 1 p34-p33 & 453 & 64 & 9 & 5 & 7 & 3 & -25.0 & -39.0 \\
\hline
\end{tabular}

*Nsig med, median derived from "signal" of 10 normal mucosae of the sigmoid and rectosigmoid.

†IQ interquartile, difference between the 75th and 25th percentiles.

\#Bsig med, median derived from "signal" of eight Dukes' B adenocarcinomas of the sigmoid and rectosigmoid.

$\S$ Csig med, median derived from "signal" of seven Dukes' C adenocarcinomas of the sigmoid and rectosigmoid.

"FC, fold change, corresponding to the "signal ratio" of Nsig med/Bsig med or Nsig med/Csig med, was calculated from the "signal log ratio".

UG cluster, UniGene cluster (http://www.ncbi.nlm.nih.gov/UniGene).

same patient in five cases, and in those 10 cases where a matching normal sample was not present, we compared each of the 10 tumours to each of five single normal samples (for details see material and methods). We identified 186 genes significantly differentially expressed more than 2.8 fold $(\mathrm{p}<0.05$, Mann-Whitney $U$ test) from the normal mucosa to Dukes' B or Dukes' C tumours (see supplementary table 3 on the Gut website at http://www.gut.com/supplemental). The majority confirmed our recently published findings made on pools of colorectal cancer samples ${ }^{11}$; for example, downregulation of nuclear encoded mitochondrial genes such as TST thiosulfate sulfurtransferase (rhodanese) (4.5-fold) and the SCAD gene 5' UTR exon 1 and 2 (sevenfold). The 42 most important genes with a fold change $\geqslant 4(\mathrm{p}<0.01)$ in both Dukes' B and Dukes' C are shown in table 3. Other genes (for example, osteopontin) which showed changes have been omitted here because changes were found to be $\geqslant 4$ fold in either Dukes' C or Dukes' B but not in both.

Thirty genes were found to be downregulated in cancer, such as GCAP-II (33-fold), carbonic anhydrase IV (33-fold), and DTD sulfate transporter gene (20-fold). Only 12 genes were upregulated, among these microsomal dipeptidase (MDP4, MDP7; 20-fold) and interleukin 8/MDNCF (15-fold). As a novel finding we found that carbonic anhydrase VII 
Table 4 Sixteen genes differentially expressed more than threefold ( $p<0.05$ ), comparing Dukes' B and C adenocarcinomas of the caecum with those of the sigmoid or rectosigmoid

\begin{tabular}{|c|c|c|c|c|c|c|c|c|c|c|}
\hline \multirow[b]{2}{*}{ Probe set ID } & \multirow[b]{2}{*}{ Gene name } & \multirow[b]{2}{*}{ Symbol } & \multirow[b]{2}{*}{$\begin{array}{l}\text { UG } \\
\text { cluster }\end{array}$} & \multirow[b]{2}{*}{$\begin{array}{l}\text { Cyto } \\
\text { band }\end{array}$} & \multicolumn{3}{|c|}{ Dukes' B } & \multicolumn{3}{|c|}{ Dukes' C } \\
\hline & & & & & $\begin{array}{l}\text { Bcae } \\
\text { med* }^{*}\end{array}$ & $\begin{array}{l}\text { Bsig } \\
\text { med } †\end{array}$ & $\begin{array}{l}\text { Avg FC } \\
\text { Bcae v } \\
\text { Bsig } ¥\end{array}$ & $\begin{array}{l}\text { Ccae } \\
\text { med } \$\end{array}$ & $\begin{array}{l}\text { Csig } \\
\text { medq }\end{array}$ & $\begin{array}{l}\text { Avg FC } \\
\text { Ccae v } \\
\text { Csig }\end{array}$ \\
\hline D00654_at & $\begin{array}{l}\text { Enteric smooth muscle } \\
\text { gamma-actin gene }\end{array}$ & ACTG2 & Hs.78045 & $2 p 13$ & 88 & 164 & -2.7 & 87 & 465 & -5.6 \\
\hline D13643_at & 24-dehydrocholesterol reductase & DHCR24 & Hs.75616 & $1 p 33-p 31.1$ & 453 & 377 & 1.4 & 503 & 197 & 3.2 \\
\hline D17408_s_at & $\begin{array}{l}\text { Calponin 1, basic, } \\
\text { smooth muscle }\end{array}$ & CNN1 & Hs. 21223 & 19p13.2-p13.1 & 47 & 105 & -2.7 & 79 & 281 & -4.5 \\
\hline D90279_s_at & Collagen, type V, alpha 1 & COL5A1 & Hs. 146428 & $9 q 34.2-q 34.3$ & 3 & 7 & -1.6 & 21 & 158 & -4.1 \\
\hline $\begin{array}{l}\text { HG2743- } \\
\text { HT2846_s_at }\end{array}$ & $\begin{array}{l}\text { Caldesmon } 1 \text { Alt. Splice } \\
6 \text { Non-Muscle (M641 10) }\end{array}$ & CALDI & Hs.325474 & $7 q 33$ & 42 & 88 & -2.2 & 57 & 306 & -4.4 \\
\hline $\begin{array}{l}\text { HG2743- } \\
\text { HT3926_s_at }\end{array}$ & $\begin{array}{l}\text { Gamma-glutamyltransferase } 1 \\
\text { (J04131) }\end{array}$ & GGT1 & Hs. 284380 & $22 q 11.1-q 11.2$ & 10 & 29 & -2.9 & 30 & 96 & -4.4 \\
\hline M26679_at & Homeo box A5 & HOXA5 & Hs.37034 & 7p15-p14 & 30 & 17 & 1.8 & 59 & 15 & 3.4 \\
\hline M58459_at & Ribosomal protein S4, Y-linked & RPS4Y & Hs. 180911 & Ypl1.3 & 6 & 157 & -8.8 & 9 & 560 & -23.3 \\
\hline M83216_s_at & Caldesmon 1 & CALD1 & Hs. 286238 & $7 q 33$ & 27 & 106 & -2.8 & 84 & 466 & -4.2 \\
\hline M84526_at & $\begin{array}{l}\text { D component of complement } \\
\text { (adipsin) }\end{array}$ & DF & Hs. 155597 & $19 p 13.3$ & 249 & 74 & 2.0 & 39 & 112 & -5.4 \\
\hline M95787_at & Transgelin 11 (SM22-alpha) & TAGLN & Hs.75777 & $11 q 23.2$ & 360 & 663 & -2.0 & 542 & 3600 & -5.3 \\
\hline U28368_at & Inhibitor of DNA binding 4 & ID4 & Hs. 34853 & $6 p 22-p 21$ & 4 & 16 & -2.0 & 4 & 38 & -5.4 \\
\hline U35139_at & Necdin (mouse) homolog & NDN & Hs.50130 & $15 q 11.2-q 12$ & 23 & 33 & -1.6 & 9 & 58 & -5.7 \\
\hline U48959_at & Myosin, light polypeptide kinase & MYLK & Hs. 211582 & $3 q 21$ & 83 & 168 & -2.3 & 146 & 618 & -5.8 \\
\hline U52191_s_at & $\begin{array}{l}\text { SMC (mouse) homolog, Y } \\
\text { chromosome }\end{array}$ & SMCY & Hs. 80358 & Yq11 & 2 & 15 & -4.6 & 2 & 48 & -12.2 \\
\hline X51405_at & $\begin{array}{l}\text { Carboxypeptidase E (EC } \\
3.4 .17 .10)\end{array}$ & CPE & Hs.75360 & $4 q 32.3$ & 10 & 22 & -2.5 & 13 & 46 & -4.1 \\
\hline
\end{tabular}

*Bcae med, median derived from "signal" of five Dukes' B adenocarcinomas of the caecum.

†Bsig med, median derived from "signal" of eight Dukes' B adenocarcinomas of the sigmoid and rectosigmoid.

IFC, fold change, corresponding to the "signal ratio", was calculated from the "signal log ratio".

$\S$ Ccae med, median derived from "signal" of five Dukes' C adenocarcinomas of the caecum.

"Csig med, median derived from "signal" of seven Dukes' C adenocarcinomas of the sigmoid and rectosigmoid.

UG cluster, UniGene cluster (http://www.ncbi.nlm.nih.gov/UniGene).

(CA VII) was decreased more than fourfold from normal to Dukes' B and C adenocarcinomas.

\section{Comparison D: tumours from the caecum versus sigmoid/rectosigmoid}

Within each of the Dukes' B and C stages, we compared all adenocarcinomas from the left side with all of those from the right side of the colon. We identified five genes in Dukes' B, 39 in Dukes' C, and five genes in both B and C, that showed significant differences in expression levels $(\mathrm{p}<0.05)$ with an average fold change of 2.8 , corresponding to a total of 44 genes differentially expressed in left and right sided tumours (see supplementary table 4 on the Gut website at http:// www.gut.com/supplemental). Among these 44 genes, 16 showed more than threefold upregulation or more than fourfold downregulation (table 4).

Differential gene expression was more common in Dukes' C than in Dukes' B, and among the genes were caldesmon 1, involved in cellular mitosis and receptor capping, modulator recognition factor 2 (a DNA binding factor), ARHB, involved in signal transduction, transgelin 11 (SM22-alpha), and D component of complement (adipsin, involved in proteolysis and peptidolysis), all five showing higher expression in left sided carcinomas. In contrast, homeobox A5 protein, a sequence specific transcription factor, was more strongly expressed in Dukes' $\mathrm{C}$ adenocarcinomas of the right side of the colon.

\section{Comparison E: comparison to identify genes in common or differentially expressed in right sided versus left sided tumours}

A total of 186 genes previously identified to be differentially expressed from normal mucosa to tumour in the left side of the colon were compared with 118 genes identified in the right colon. This resulted in 30 common cancer genes being significantly differentially expressed more than threefold (accompanied by a p value of $<0.05$ ) in at least one of the Dukes' in both right sided as well as left sided tumours. These may make ideal colonic tumour markers (table 5).

Validation of the results by real time PCR applied to aminopeptidase N/CD13, SCAD, and PCK1 is shown in fig 2 where single GeneChip analyses were compared with real time PCR analyses. Additionally, we identified cancer genes being characteristic for one side of the colon only. Eighty eight genes shown in supplementary table 5 (on the Gut website at http://www.gut.com/supplemental) were significantly differentially expressed exclusively in right sided tumours, such as factor XIII subunit a and calcium binding protein S100P (fig 2), suggesting a more crucial role in caecal adenocarcinomas. A total of 156 genes shown in supplementary table 6 (on the Gut website at http://www.gut.com/ supplemental) were significantly differentially expressed only in left sided tumours. Among these were MDP4/MDP7 and the interferon inducible protein "9-27". Differences in expression in most of the growth factors were seen in the left colon such as upregulation of teratocarcinoma derived growth factor ( $>7$ fold). Furthermore, the COX-2 gene was more than sixfold higher in Dukes' $C$ tumours of the left colon, and did not show a significant difference in right sided tumours. Most strikingly, expression of keratins 8, 19, and 20 was severely reduced in the left colon but did not show significant differences in the caecum.

\section{Microsatellite analysis}

Microsatellite analysis was performed on microdissected tumour tissue, as described in materials and methods in the supplementary data (on the Gut website at http:// www.gut.com/supplemental). Of 10 samples, where the amount of tissue allowed microdissection, only one sample (No 120B) was found to be highly microsatellite instable, the 


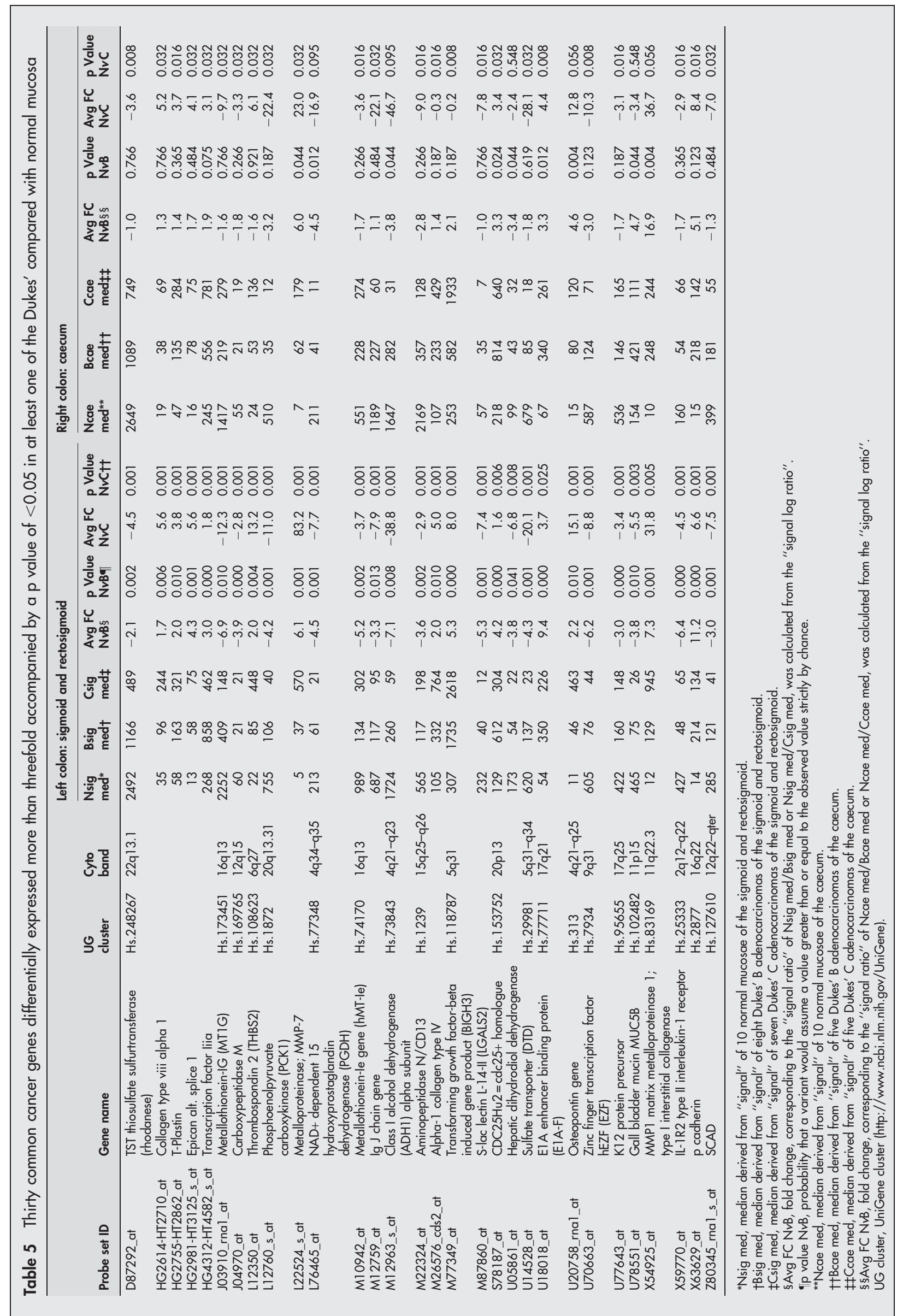



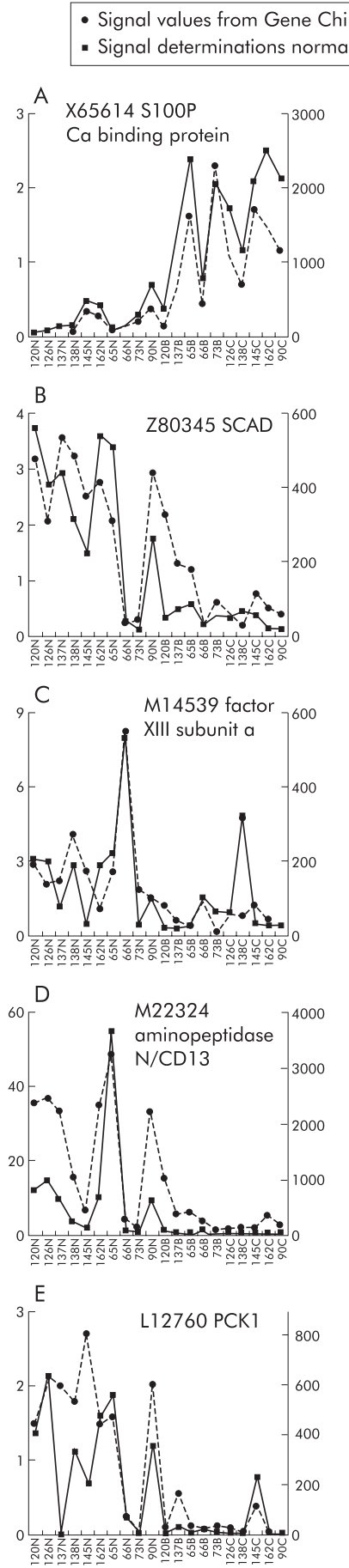

Figure 2 Comparison of single GeneChip analyses with real time polymerase chain reaction (PCR) analyses. Expression analyses of five selected genes using single samples of normal colon mucosa and adenocarcinomas of Dukes' stages $B$ and $C$ from the right $(A-E)$ and left $(\mathrm{F}-\mathrm{J})$ sides of the colon. Left $\mathrm{y}$ axis shows expression intensities "normalised to GAPDH" obtained from reverse transcription (RT)-PCR and the right $y$ axis shows expression intensities "signal" derived from GeneChip analysis. (A, F) X65614 S100P Ca-binding protein; (B, G) Z80345 SCAD; (C, H) M14539 factor XIII subunit a; (D, I) M22324 aminopeptidase N/CD13; (E, J) L12760 PCK1 (phosphoenolpyruvate carboxykinase).

other nine samples being microsatellite stable (MSS), as listed in supplementary table 1 (on the Gut website at http:// www.gut.com/supplemental). The fact that all except one of the tumours were stable with regard to microsatellites BAT25 and BAT26 (MSS) strongly supports the conclusion that the differences described here do not result from differences in microsatellite stability but have to be regarded as differences characterising the function and behaviour of tumours originating from the caecum or sigmoid and rectosigmoid.

\section{Immunohistochemical analysis}

Immunostaining was applied to paraffin embedded specimen from eight of the 10 right sided and 11 of the 15 left sided tumours where snap frozen material had been previously analysed on microarrays to enable a comparison of RNA and protein expression. The 19 tumours where selected based on the availability of their matching normal mucosa from the oral resection edge.

Figure 3 (A, B) shows five right and five left sided tumours with their matching normal mucosa stained with COX-2. In the right colon, COX-2 was moderately to strongly expressed in normal mucosa, mostly throughout the entire epithelium as well as in right sided tumours. Comparing normal tissue with tumour, we detected upregulation (in one of eight tissue sections), downregulation ( $1 / 8)$, or about equal expression in normal tissue and tumour (6/8). In the left side of the colon, COX-2 was not or only very weakly expressed in normal mucosa and was upregulated from normal mucosa to tumour. Comparing normal mucosa to tumour, we observed strong upregulation in more than $50 \%$ of cells (3/11), moderate upregulation in more than $50 \%$ of cells $(5 / 11)$, and very strong upregulation in single cell groups corresponding to less than $10 \%$ of cells (3/11).

Figure 3 (C, D) shows five right and five left sided tumours with their matching normal mucosa stained with cytokeratin 20 (KRT20). KRT20 was strongly expressed in the luminal epithelium of normal mucosa of both sides. Comparing normal tissue to tumour of the right side, we detected strong upregulation with staining of more than $50 \%$ of cells $(2 / 8)$, downregulation (4/8) with staining of less than $10 \%$ of cells, or about equal expression in normal and tumour with staining of approximately $30-40 \%$ of tumour cells $(2 / 8)$. Comparing normal mucosa to tumour on the left side, we observed upregulation with staining of more than $50 \%$ of cells $(2 / 11)$, downregulation with staining of less than $10 \%$ of cells $(7 / 11)$, or about equal expression in normal mucosa and tumour with staining of approximately $30-40 \%$ of tumour cells $(2 / 11)$. Staining of tumour cells was very heterogeneous in most of the tumours.

\section{DISCUSSION}

While published data on right sided versus left sided colon cancers are lacking, colon cancers per se have previously been compared with normal mucosa. In this study, we identified differences in gene expression in the colon that characterised left and right sided normal mucosa and adenocarcinomas. Using statistical algorithms provided by the Affymetrix software, we identified sets of genes differentially expressed, as well as genes in common, between right sided and left sided adenocarcinomas.

In this study, we analysed a total of 45 samples (20 normal and 25 tumour samples). The complexity of our study is comparable with colon cancer expression analyses previously described by Alon et al, analysing 22 normal and 40 tumour samples, and by Notterman et al, analysing 18 adenocarcinomas and four adenomas with paired normal tissue, both using Affymetrix GeneChips, as previously discussed..$^{12}{ }^{13}$ The reliability of our data (for example, with regard to comparisons of left sided normal mucosa to Dukes' B and C tumours) is supported by the fact that we confirmed identification of various genes previously identified by other techniques. Metallothionein, fibronectin, and SPARC, for example, had previously been shown to be differentially 
A

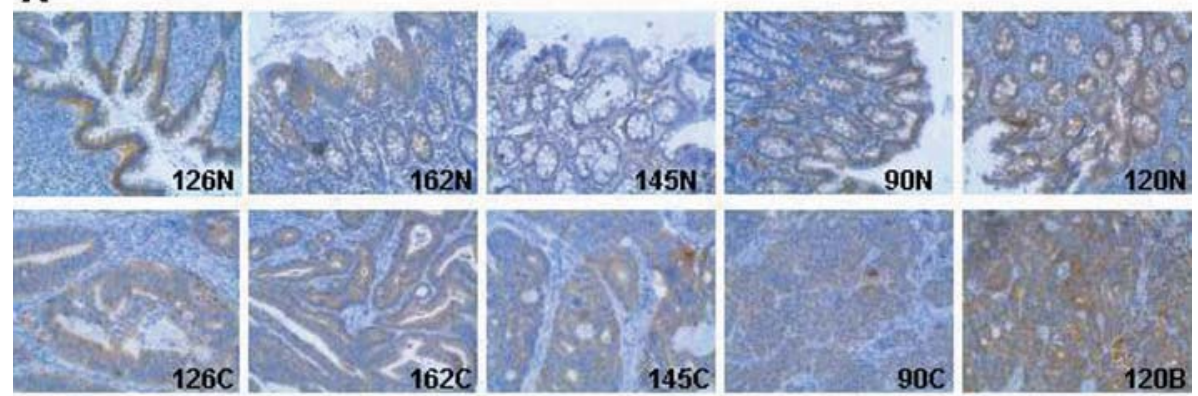

B
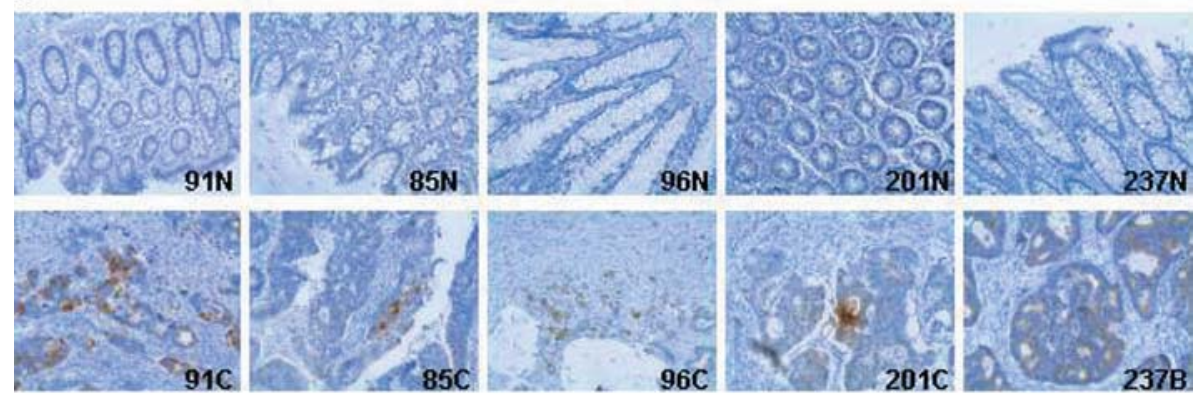

C
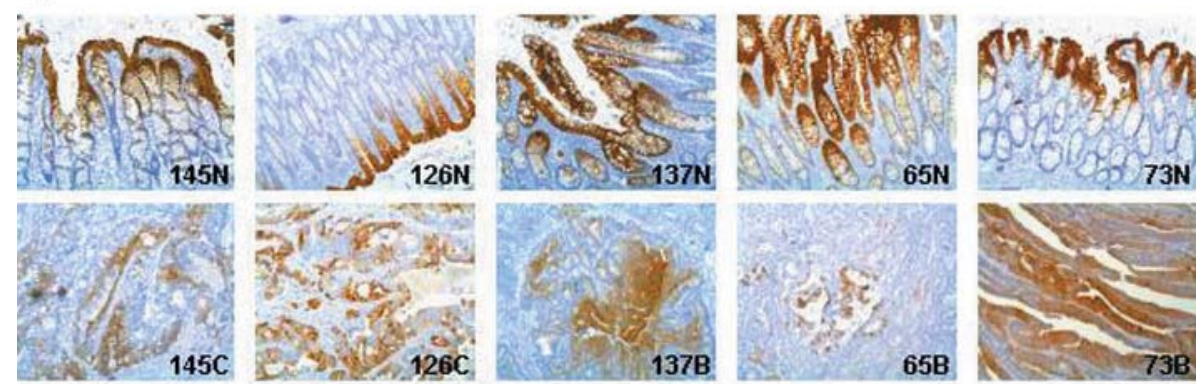

D
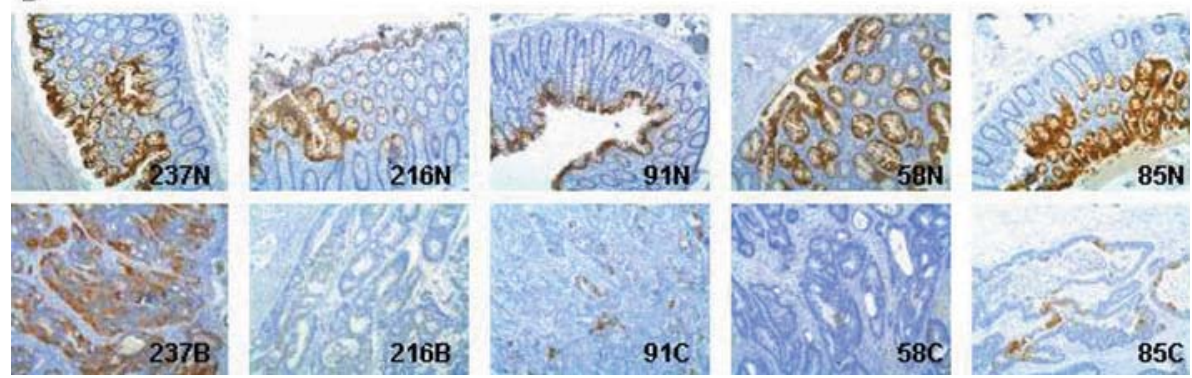

Figure 3 Immunohistochemistry of formalin fixed paraffin embedded sections of Dukes' B and C adenocarcinomas and their matching normal mucosa (N). Sample numbers of tumours refer to samples previously analysed on microarrays. Cyclooxygenase 2 (COX-2) was moderately expressed in right sided normal mucosa as well as in matching tumours (A). COX-2 was not or very weakly expressed in left sided normal mucosa but moderately to strongly expressed in matching tumours showing a very heterogeneous staining pattern (B) (magnification 20x). Cytokeratin 20 (KRT20) was highly expressed in the luminal epithelium of normal mucosa of both sides. KRT20 was downregulated in only $50 \%$ of right sided tumours (C) whereas it was strongly downregulated in $80 \%$ of left sided tumours (D) (magnification 10x).

expressed in normal tissue and tumour by Zhang et al, using the SAGE technique on two normal and two tumour samples. ${ }^{14}$ Furthermore, we confirmed differential expression of more than $70 \%$ of genes previously identified by GeneChip analyses of pooled samples of the left side of the colon. ${ }^{11}$ In addition, these results were also highly comparable with data previously published by Notterman et al (for example, upregulation of MGSA from normal to tumour tissue and downregulation of guanylin or chromogranin A). ${ }^{13}$ Reliability of the results with regard to differences between the right and left colon was further supported by expression analysis using RT-PCR showing high reproducibility of expression levels detected by the arrays. Previous studies have, in most cases, not taken into account the Dukes' stage or location within the colon where the samples originated. Obviously, adding more subclasses to the material inevitably leads to fewer samples per class and the main findings of this paper should be repeated on larger material.

A grouped Mann-Whitney test intrinsic to the Affymetrix software DMT 3.0 was used for statistical analyses. As some of the data were paired (different tissues from the same patient) a Wilcoxon matched pairs test may have been more 
appropriate for these cases and this may have been a limitation of our statistical analyses. On the other hand, some of the samples were grouped (tissue from different patients) and a Mann-Whitney test had to be applied. However, such "breaking of matching" is more likely to make the results more, rather than less, comparable between tumour and normal tissue, and so this limitation is not of major importance as it is not likely to explain any of the observed differences.

We focused the analysis on adenocarcinomas of Dukes' stages $\mathrm{B}$ and $\mathrm{C}$ as these are the most challenging stages in colon cancer, with the possibility of curative treatment. Most of the factors that may influence gene expression were taken into account but for array analysis it was not possible to match all samples with their normal mucosa (as could be achieved for immunostainings) or to match samples with regard to sex, as most of our right sided colon cancer patients were female. In general, colon cancer affects males and females equally but some studies indicate that right sided colon cancer affects more women than men. ${ }^{2}$ Comparison of right versus left sided normal mucosa showed 58 genes differentially expressed, 12 with fold changes more than threefold and none located on the Y chromosome. A comparison of right and left sided adenocarcinomas showed two genes located on the Y chromosome and significantly higher expressed in the group of left sided Dukes' $\mathrm{C}$ but not Dukes' B. RPS4Y and SMCY show high fold changes of 23and 12 -fold but SMCY increases only up to a signal of 50 , which is close to the detection level. From these data there is no evidence that the imbalance between males and females influences the results profoundly.

Genes such as $\beta$-catenin, c-erbB2, EGFR, PCNA, or DPP IV, previously shown to be differentially expressed in right and left colon cancers, ${ }^{9}$ were not identified as significant in this study but did show side differences when less stringent selection criteria were applied. There are many factors affecting gene expression analysis, such as ischaemic delay, defined as the period of time from clamping of blood vessels to snap freezing, ratio of tumour versus non-tumour cells, RNA extraction method and quality of RNA (28s/18s ratio), type of array used (c-DNA arrays, nylon membrane, oligonucleotide arrays), amplification, labelling (Cy3/Cy5 or d-UTP-Biotin/SAPE) and labelling efficiency, sensitivity and detection threshold, software used for analysis, and statistical significance criteria.

The most predominant differences between normal left and right colon mucosa were higher expression in left sided mucosa of genes such as pS2 protein, calcium binding protein S100P, HOXB13, SIAT4C, and WFDC2. This agrees with previous findings of a 7.7-fold higher expression of pS2 protein $^{15}$ and approximately fourfold higher expression of HOXB13 and $\mathrm{S}_{100 \mathrm{P}^{10}}$ in the left colon. This agreement is remarkable because different platforms have been used for analysis and two thirds of the samples in the study of Glebov et al were HNPCC samples. Homeobox proteins such as HOXB13 or HOXA5 encode transcription factors and upregulate tumour suppressor p53 and may therefore be involved in side specific tumorigenesis.

Defensin 5 was found to be expressed sixfold higher in right sided mucosa which matches the proposal that the right colon provides more efficient local tumour defence, maintaining the mucosal barrier. ${ }^{5}{ }^{16}$ We hypothesise that the right sided colon mucosa provides protection against carcinogens by defensin 5 expression, leading to less frequent carcinogenesis compared with the left side. Remarkably, the site on chromosome $8 p$ housing the defensin gene is frequently lost in liver metastases from primary colon cancers. ${ }^{15}$

The majority of genes found to be differentially expressed from normal mucosa to Dukes' $\mathrm{B}$ or $\mathrm{C}$ of the left side confirmed our recently published findings performed on pooled samples. ${ }^{11}$ Genes such as MDP4/MDP7 and interleukin 8/MDNCF were strongly upregulated, and several nuclear encoded mitochondrial proteins such as rhodanese or SCAD were strongly downregulated in tumours. We also identified reduced levels of several carbonic anhydrases (CA) such as CAVII or CAIV which have not previously been described indepth in colon cancer. CAIV, downregulated by up to 33-fold in left sided tumours, is responsible for maintenance of $\mathrm{pH}$ and ion equilibrium. Takenawa et al showed that low level expression of CAIV and aquaporin 1 in renal cell carcinomas was associated with poor survival. ${ }^{17}$

Notterman et al analysed differential gene expression between the normal colon and tumour, without discriminating between the right and left side. ${ }^{13}$ In terms of expression differences between normal mucosa and tumour of the left colon, our study is highly comparable with that of Notterman et al. In both studies, prior to analyses samples were defined with regard to Dukes' stage, snap frozen bulk tissue samples yielded high quality RNA, identical labelling and GeneChips were used, and the data were analysed using the MannWhitney $U$ test. Notterman et al identified CAIV as being downregulated by 38 -fold from normal colon to tumour, which is identical to our results. In summary, this strongly supports the hypothesis that a decrease in CAIV expression is linked to carcinogenesis and colon cancer progression.

Expression of genes such as COX-2, caldesmon 1, adipsin, transgelin 11, and ARHB was found to be higher in left sided compared with right sided adenocarcinomas. A previous study showed a better effect of chemoprevention with nonsteroidal anti-inflammatory drugs on right sided than on left sided adenocarcinomas, ${ }^{3}$ and the sixfold higher expression of COX-2 may explain failure to prevent this, as a higher dose may be needed to inhibit the high levels of this molecule in left sided malignant lesions. Loss of transgelin gene expression may be an important early event in tumour progression as a consequence of deregulation of RAS gene expression through RAF independent pathways. ${ }^{18}$ Interestingly, ARHB (RhoB), located on chromosome 2pter-pl2, is one of three RAS homologue gene family members and is known as an oncogene. ${ }^{19}$

From normal mucosa to Dukes' B and C of the caecum, we found that TRPM-2 (clusterin) and PGDH were strongly downregulated whereas several matrix metalloproteinases such as MMP1, MMP3, and MMP10 were upregulated, as seen previously in left sided tumours. MMPs are enzymes responsible for extracellular matrix degradation, playing a role in cancer progression and metastatic spreading. MMPI expression is associated with a poor prognosis in colorectal cancer. ${ }^{20}$ One possible therapeutic approach for patients with colon cancer, mainly Dukes' C, could therefore be administration of specific MMP inhibitors to prevent distant metastases and prolong survival, ${ }^{21}$ as has been shown by inhibition of MMP2 expression in mouse xenograft experiments. ${ }^{22}$ Circulating proenzymes of MMPs have been described as possible serum markers, and proMMP-9, but not proMMP-2 identified here, was found to be significantly higher in cancer sera versus normal sera. ${ }^{23}$ From a clinical approach, we suggest analysis of sera levels of the MMPs identified here, as these molecules seem to be ideal general colonic tumour markers reflecting the presence of both left and right sided colonic tumours.

In conclusion, the 30 genes identified in adenocarcinomas of both sides have to be regarded as general tumour markers. The present data and our previously published LOH analyses ${ }^{11}$ strongly support the hypothesis that genes such as aminopeptidase N (CD 13), sulfate transporter DTD, SCAD, or PCKI should be regarded as potential new tumour suppressors requiring further investigation. 
Paraffin embedded tissue sections from Dukes' B and C tumours and their matching normal mucosa were subjected to immunohistochemical analysis for COX-2 and cytokeratin 20 (KRT20). Microarray analysis showed a significant decrease in KRT20 from normal mucosa to tumour in the left side of the colon. Immunostaining confirmed the difference seen between the two sides of the colon as KRT20 was strongly downregulated in $80 \%$ of left sided tumours compared with $50 \%$ of right sided tumours. In general, KRT20 staining was found to be very heterogeneous within the tumours.

COX-2 microarray data showed that COX-2 was upregulated from normal to Dukes' $\mathrm{C}$ in right as well as left sided tumours, but the increase was significant only for left side $(p<0.005)$. Immunostainings support the microarray based findings to date, that COX-2 is not or very weakly expressed in left sided mucosa but upregulated in matching tumours. In contrast, COX-2 is expressed with the same intensity in right sided normal mucosa compared with matching tumours. COX-2 is heterogeneously expressed within a tumour, as only some groups of cells within a tumour are stained. In conclusion, the microarray based findings were confirmed by immunohistochemistry but an absolute quantitative comparison between RNA expression on microarrays and protein expression on tissue specimen is not possible for KRT20 and COX-2 due to their heterogeneous staining patterns.

The existence of a side specific expression difference for COX-2, having been identified by microarray analysis and confirmed by immunohistochemistry in this study, has recently been reported by Nasir and colleagues. ${ }^{24}$ Immunohistochemical staining applying a COX-2 polyclonal antibody on 18 right sided versus 18 left sided adenocarcinomas showed that COX-2 positivity was significantly higher for left compared with right sided tumours.

We conclude that differences in gene expression between normal mucosa as well as adenocarcinomas of the caecum and sigmoid and rectosigmoid colon clearly exist, and we hypothesise that the difference in gene expression could be related to differences in tumour development and the prognosis of patients.

The emerging treatments directed towards specific molecular targets should emphasise the differences seen in right and left sided tumours of the colon. We suggest that some of the highly expressed molecules that are in both left and right sided colonic adenocarcinomas may be promising new potential serum markers and therapy targets.

\section{ACKNOWLEDGEMENTS}

We thank Bente Devantier, Ing Lis Thorsens, and Annette B. Nielsen for their technical assistance, and also as project-nurse Edith Kirkedahl Nielsen at Aarhus Sygehus for collection of colon tissue samples. The study was supported by funds from the Karen Elise Jensen Foundation, the Danish Research Council, AROS Applied Biotechnology Aps, Aarhus, the University and County of Aarhus, the Nordic Cancer Union, and the European Union's 5th frameprogram (European Community, No QLG2-CT-2001-01861).

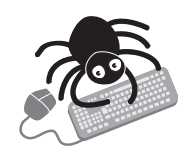

All supplementary data and supplementary tables 1-7 can be viewed on the Gut website at http:// www.gut.com/supplemental.

\section{Authors' affiliations}

K Birkenkamp-Demtroder, S H Olesen, T F Ørntoft, Molecular Diagnostic Laboratory, Department of Clinical Biochemistry, Aarhus University Hospital/Skejby Hospital, Aarhus N, Denmark

F B Sørensen, Institute of Pathology, Aarhus University Hospital, Aarhus Sygehus, Aarhus C, Denmark

S Laurberg, Surgical Department L, Aarhus University Hospital, Aarhus Sygehus, Aarhus C, Denmark

P Laiho, L A Aaltonen, Department of Medical Genetics, Biomedicum, University of Helsinki, Helsinki, Finland

Conflict of interest: None declared.

\section{REFERENCES}

1 Campbell F, Appleton MA, Shields CJ, et al. No difference in stem cell somatic mutation between the background mucosa of right- and left-sided sporadic colorectal carcinomas. J Pathol 1998;186:31-5.

2 Distler P, Holt PR. Are right- and left-sided colon neoplasms distinct tumors? Dig Dis 1997; 15:302-11.

3 lacopetta B. Are there two sides to colorectal cancer? Int J Cancer 2002;101:403-8.

4 Konishi K, Fujii T, Boku N, et al. Clinicopathological differences between colonic and rectal carcinomas: are they based on the same mechanism of carcinogenesis? Gut 1999;45:818-21.

5 Reifferscheid $M$, Fass J, Hartung R, et al. Special aspects of right colon cancer. Langenbecks Arch Chir 1987;371:193-200.

6 Tomoda H, Taketomi A, Baba H, et al. The clinicopathological characteristics and outcome of patients with right colon cancer. Oncol Rep 1998;5:481-3.

7 Elsaleh H, Joseph D, Grieu F, et al. Association of tumour site and sex with survival benefit from adjuvant chemotherapy in colorectal cancer. Lancet 2000;355:1745-50.

8 Kapiteijn E, Liefers GJ, Los LC, et al. Mechanisms of oncogenesis in colon versus rectal cancer. J Pathol 2001; 195:171-8.

9 Fric $\mathbf{P}$, Sovova $\mathrm{V}$, Sloncova $\mathrm{E}$, et al. Different expression of some molecular markers in sporadic cancer of the left and right colon. Eur J Cancer Prev 2000;9:265-8.

10 Glebov OK, Rodriguez LM, Nakahara K, et al. Distinguishing right from left colon by the pattern of gene expression. Cancer Epidemiol Biomarkers Prev 2003; 12:755-62.

11 Birkenkamp-Demtroder K, Christensen LL, Olesen SH, et al. Gene expression in colorectal cancer. Cancer Res 2002;62:4352-63.

12 Alon U, Barkai N, Notterman DA, et al. Broad patterns of gene expression revealed by clustering analysis of tumor and normal colon tissues probed by oligonucleotide arrays. Proc Natl Acad Sci U S A 1999:96:6745-50.

13 Notterman DA, Alon U, Sierk AJ, et al. Transcriptional gene expression profiles of colorectal adenoma, adenocarcinoma, and normal tissue examined by oligonucleotide arrays. Cancer Res 2001;61:3124-30.

14 Zhang L, Zhou W, Velculescu VE, et al. Gene expression profiles in normal and cancer cells. Science 1997;276:1268-72.

15 Paredes-Zaglul A, Kang JJ, Essig YP, et al. Analysis of colorectal cancer by comparative genomic hybridization: evidence for induction of the metastatic phenotype by loss of tumor suppressor genes. Clin Cancer Res 1998:4:879-86.

16 Wehkamp J, Schwind B, Herrlinger KR, et al. Innate immunity and colonic inflammation: enhanced expression of epithelial alpha-defensins. Dig Dis Sci 2002;47:1349-55.

17 Takenawa J, Kaneko Y, Kishishita M, et al. Transcript levels of aquaporin 1 and carbonic anhydrase IV as predictive indicators for prognosis of renal cell carcinoma patients after nephrectomy. Int J Cancer 1998;\%20, 79:1-7.

18 Shields JM, Rogers-Graham K, Der CJ. Loss of transgelin in breast and colon tumors and in RIE- 1 cells by Ras deregulation of gene expression through Rafindependent pathways. J Biol Chem 2002;277:9790-9.

19 Madaule P, Axel R. A novel ras-related gene family. Cell 1985;41:31-40.

20 Murray GI, Duncan ME, O'Neil P, et al. Matrix metalloproteinase-1 is associated with poor prognosis in colorectal cancer. Nat Med 1996;2:461-2.

21 Aparicio T, Kermorgant S, Dessirier V, et al. Matrix metalloproteinase inhibition prevents colon cancer peritoneal carcinomatosis development and prolongs survival in rats. Carcinogenesis 1999;20:1445-51.

22 Oba K, Konno H, Tanaka T, et al. Prevention of liver metastasis of human colon cancer by selective matrix metalloproteinase inhibitor MMI-166. Cancer Lett 2002;175:45-51.

23 Pucci-Minafra I, Minafra S, La Rocca G, et al. Zymographic analysis of circulating and tissue forms of colon carcinoma gelatinase A (MMP-2) and B (MMP-9) separated by mono- and two-dimensional electrophoresis. Matrix Biol 2001;20:419-27.

24 Nasir A, Kaiser HE, Boulware D, et al. Cyclooxygenase-2 expression in rightand left-sided colon cancer: a rationale for optimization of cyclooxygenase-2 inhibitor therapy. Clin Colorectal Cancer 2004;3:243-7. 